\title{
The Problem of Unbalance and Inadequacy of Scientific Research Evaluation in China's Universities
}

\author{
Jianli Wang \\ Administration of Scientific Research, Nanjing University of Finance and Economics, Nanjing, \\ Jiangsu, 210023, China. \\ jianliwang@nufe.edu.cn
}

\begin{abstract}
At present, our country is undergoing a transformation from a big nation of higher education into a powerful one, the achievement of which requires the realization of high quality and innovation in scientific research evaluation. Unbalanced and inadequate development consist in quality and quantity, classified evaluation, innovation and achievement transformation, academic consciousness and academic discourse power as regards scientific research evaluation in Universities. As a result, only when an effective and reasonable scientific research evaluation system is established and the problem of unbalance and inadequacy in research evaluation is solved is it possible that university connotation construction can be promoted; the quality of talent cultivation can be improved; the transformation between scientific research achievement can be stimulated; scientific research and innovation capacities, social service level, scientific management innovation can be improved; it is of great value to strengthen research integrity and academic atmosphere construction; all of these factors can provide scientific and reasonable evaluation of whether the ultimate goal of "Double World-class" Construction can be achieved so that the target of a great power of world-class higher education with Chinese characteristics can be realized.
\end{abstract}

Keywords: Scientific research in universities, scientific research evaluation, the problem of unbalance and inadequacy.

\section{Introduction}

Xi Jinping's report at 19th CPC National Congress indicated that the principal contradiction facing has evolved into the contradiction between unbalanced and inadequate development and the people's ever-growing needs for a better life. Similarly, as part of the overall social development, this contradiction in the field of higher education is "the contradiction between unbalanced and inadequate educational development and the people's ever-growing longing for a higher and better education" [1]. It can be said that "unbalanced, inadequate development" has become frequently appearing key words in the new era. At the same time, unbalance and adequacy also exist in scientific research evaluation which is regarded as the barometer of higher education.

\section{The Problem of Unbalance and Inadequacy of Academic Consciousness and Academic Discourse Power in Scientific Research Evaluation}

There is always discussion on the relationship between "academy" and "administration" in the field of higher education in China. A large number of scholars in the field of education hold the opinion that the abuse of administration should be got rid of. The reasons why they hold this point of view lie in the fact that in many aspects in universities, administrative power overweighs academic authority. This fact leads to the result that academic discourse is attached to administration in colleges and universities. However, in essence, scientific research evaluation in colleges and universities belongs to the category of academic evaluation and it is a kind of extension of academic activities [2].In the field of university scientific research, there exists a tendency for administrative character. Administrative power over-interferes in the whole process of scientific research evaluation, which makes some features of the evaluation less and less obvious, while administrative functions become increasingly obvious. Meanwhile, in the process of scientific research evaluation, such kind of subsidiary relations cause some problems of academic atmosphere such as establishing underhand connections for personal gain, departmental selfishness, bureaucracy, etc.. In addition, the results of 
scientific research evaluation are dissimilated. For example, some titles and talent projects have marked prices in recent years when some universities want to employ the same talents, including such honorary titles as "Changjiang Scholar" and "Thousand Talents Program", etc. as well as all kinds of talent programs such as "Excellent Young Scholars" and "Distinguished Young Scholars" which are Supported by the National Natural Science Foundation of China. This phenomenon leads to the disorder of university talents fluxion in recent several years. On 30 May, the CCP central committee general office and the State Council general office printed and distributed "Proposals for Further Intensifying the Construction of Scientific Research Integrity", which requires each department in all areas to implement the regulations seriously based on practice. On 11 June, National Natural Science Foundation of China released "The Open Letter of the National Natural Science Foundation of China on Avoiding the Alienation of Talent Projects", and these two documents both show the increasingly penetrating contradictions with regard to scientific research evaluation. Unbalanced and inadequate academic discourse power in scientific research evaluation lies in the fact that academic discourse system has deficiency in international leadership and is still at the stage of being a follower. For example, the USA has SCI and SSCI, and we designed the Chinese versions CSCD and CSSCI; Europe and the USA have three leading world ranking index system QS, THE, U.S. News, correspondingly, we have our world university academic ranking standards ARWU. Such kind of imitation makes our scientific research evaluation play a less decisive role in the world. This feature becomes more obvious when general secretary $\mathrm{Xi}$ proposed the ideas of "destiny of mankind community", "one belt, one road" as well as "Double World-class" Construction. Under such background, we need Chinese characteristics in scientific research evaluation very much. In May, 2018, general secretary Xi emphasized "The development of a country complements the development of universities, we can make higher education better during the process of national development. As a result, we have to focus on Chinese characteristics if we want to set up world-class universities." when he paid a visit to Peking University.

\section{The Problem of Unbalance and Inadequacy of Quality and Quantity in University Scientific Research Evaluation}

In the 1960s, scientometric indicators were applied to scientific research evaluation. Compared with peer review system which is subjective and focuses on quality, this quantitative evaluation which is based on scientometrics has objective criterion, to some extent. Its quantitative evaluation itself consists of two factors -- quantity and quality. In scientometrics, the five indexes including the number of theses, total cited times, influencing factors, the number of co-authors, $\mathrm{h}$ index all shows the unity of quality and quantity [3]. At present, the university scientific research evaluation in China mainly deals with the combination of peer evaluation and quantitative evaluation. During the process of evaluation, not only it is necessary to have general requirement of the quantity of scientific research evaluation, but also requirement of quality is a must. However, the phenomenon of emphasizing too much on quantity and neglecting quality is a potential problem for scientific research evaluation in China. There is the problem of unbalance and inadequacy of quality and quantity during this course. At present, the assessment of scientific research in China's universities usually specifies the quantity of theses and monographs, which stresses short-term benefit and therefore leads to the result that some of the scientific researchers simply pursue quantity to seek quick benefit. In the past twenty years, SCI papers showed exponential growth [4], however, the papers rarely have great international influence and significant innovation. Just as academician Li Guojie indicates in Guangming Daily, "SCI itself is not a problem, the problem consists in the fact that we are abusing it." [5].The present situation with regard to scientific research evaluation in China is that researchers may overuse SCI, SSCI, CSSCI and other indicator systems without critical thinking about it. What's more, universities have specific requirement of quantity of papers published in SCI, SSCI and CSSCI during the course of professional title appraisal, talent selection, declaration of awards and other similar aspects. They simply think that the quality of articles published in SCI, SSCI, CSSCI is much higher that of articles in other journals, and frequently cited articles in other journals instead of these three are completely 
eliminated or left unused. There exists the phenomenon that quantity comes first if the quality is not high enough, especially during the course of professional title appraisal. That is to say, even though the quality of scientific research achievements are not to the standards prescribed by the regulations of professional title appraisal, the requirements of quality can be met by lowering the quality and raising the quantity.

\section{The Problem of Unbalance and Inadequacy of Classified Evaluation in University Scientific Research Evaluation}

Not only the documents in "Proposals of the Ministry of Education for Further Improving the Evaluation of Philosophy and Social Sciences in Universities" promulgated in 2011, but also those in "Proposals of the Ministry of Education for Intensifying the Reform of Scientific and Technological Evaluation in Universities" promulgated in 2013 specifies clearly that universities are expected to implement scientific and rational classified evaluation and that an all-around classified evaluation criterion system should be established. Meanwhile, a scientific and reasonable criterion with specific emphasis is supposed to be established respectively which includes scientific research integrity and academic atmosphere, contribution and equality of innovation, joint talent cultivation with the help of integration of research and education, science communication and popularization. The establishment of the criterion should take the following factors into consideration: different opinion targets such as related people, projects, organizations and achievements, different disciplines such as Humanities and Social Science as well as Natural Science, working characteristics like basic research, technological transformation of applied research and achievement transformation, etc.. However, in recent years, classified evaluation criterion is implemented ineffectively and the effect is not significant enough. The criterion is not adjusted according to different levels, different types or different disciplines of universities with the help of various elements. No matter whether it is a research-oriented university or an application-oriented university, no matter whether it is an undergraduate universities or a vocational college, no matter whether it is a comprehensive university or a university with similar and relatively fewer disciplines, no matter whether it is evaluation of talents or evaluation of projects and achievements, the scientific research evaluation of which all tend to be homogeneous. Currently, universities do have scientific research evaluation and its incentive mechanism, but teachers' academic abilities are mainly measured by the quantity of papers and monographs as well as how much the research funds are. With regard to this, on 3 July, 2018, the CCP central committee general office and the State Council general office printed and distributed "Proposals for Intensifying the Reform of Project Appraisal, Talent Evaluation and Institutional Evaluation", and classified evaluation was required one more time in the evaluation document. Classified evaluation system has basically formed which adjusts to the requirement of innovationdriven development, accords with the laws of scientific and technological innovation and also highlights quality, contributions and performance as well.

\section{The Problem of Unbalance and Inadequacy of Innovation and Achievement Transformation in Scientific Research Evaluation}

On 28 May, 2018, in the 19th General Assembly of Chinese Academy of Sciences and the 14th General Assembly of Chinese Academy of Engineering, Chairman Xi emphasized again that we should realize innovation is the first driving force. He also indicated that innovation decides our future and we should persist with scientific and technological innovation, we should optimize and intensify top-down design of innovation system. In addition, he thinks we should have an accurate evaluation of the scientific value, technological value, economic value, social value and cultural value of scientific and technological innovation achievements. What's more, scientific research evaluation system should be reformed to fulfill its due value. Since that the present scientific research evaluation system in universities has the disadvantages of short time and low quality, regulated quantity of scientific research achievements in a particular time limit is required regardless of the present 
professional title evaluation system or the talent evaluation system. The reason why quite a large number of university scholars give up the internal quality of scientific research innovation and begin to pursue a large quantity is due to the internal pressure of professional titles and talent development; the other reason why this phenomenon takes place is that there is a lot of pressure of quantitative requirements. All these lead to the result that a lot of research is frequently repeated without any kind of innovation and their only focus and pursuit are quantity and speed of scientific research. Another problem of unbalance and inadequacy in university scientific research evaluation is the insufficient emphasis on technology transfer and achievement transformation, which problem causes the inferior transforming capabilities of achievements and disconnection of industry, university and research. The present scientific research evaluation in universities attaches more importance to academic benefit instead of market benefit. As a result, many college professors only regard patent application as a tool used for professional titles as well as talent evaluation, as a task, at the same time. Once they get their accredited professional titles, they will leave their application discarded, which is particularly a kind of instrumental rationality. A large number of patents have become invalid because there is no maintenance afterwards, and many patents are only at the stage of academic benefit. The application of patents only work as the criterion of assessing teachers' achievements in universities instead of being applied to the market and having its due value.

\section{Summary}

The problem of unbalance and inadequacy in scientific research evaluation has a profound influence on the development of scientific research in China's universities and this year is said to be "the year of scientific research evaluation in universities". Not only the speeches given by the central leading group but also the documents released by related various departments show that the problems in the field of university scientific research evaluation emerged. On $28 \mathrm{May}, 2018$, in the 19th General Assembly of Chinese Academy of Sciences and the 14th General Assembly of Chinese Academy of Engineering, Chairman $\mathrm{Xi}$ made a speech as regards intensifying the reform of scientific and technological systems; On 16 May, 2018, the CCP central committee printed and distributed "Proposals for Speeding Up the Construction of Philosophy and Social Sciences with Chinese Characteristics"; On 30 May, 2018, the CCP central committee general office and the State Council general office printed and distributed "Proposals for Further Intensifying the Construction of Scientific Research Integrity"; On 3 July, 2018, the CCP central committee general office and the State Council general office printed and distributed "Proposals for Intensifying the Reform of Project Appraisal, Talent Evaluation and Institutional Evaluation". All the speeches and documents require that scientific research evaluation system should be further reformed and the classified evaluation system which lays importance to quality, contributions and achievements of scientific and technological innovation should be established. Since the reform and development of higher education, no other central leading groups have paid so much attention to scientific research evaluation in universities, what's more, the documents which require that the reform of scientific research evaluation system should be intensified is released the most frequently.

At present, our country has transformed from a big educational nation into a powerful one, and higher education is undergoing a transformation from a quantitative into a qualitative pattern, from an extensional mode into an intensional one. However, the obtainment of high-quality higher education can only be accomplished through the formative evaluation-scientific research evaluation which attaches great importance to quality and innovation. Only when an effective and reasonable scientific research evaluation system is established and the problem of unbalance and inadequacy in the present scientific research evaluation is solved can universities' intension construction be promoted; the quality of talent cultivation be improved; social service and the transformation of scientific research evaluation be stimulated; scientific research innovation capabilities and social service levels be improved; innovation of scientific research management be promoted; scientific research integrity and academic atmosphere construction be intensified. Under all these conditions, they can provide scientific and reasonable evaluation for whether our "double 
world-class" construction can achieve its ultimate aim, thus realizing the goal of building a powerful country with world-class higher education and Chinese characteristics.

\section{Acknowledgements}

The Project of University Philosophy and Soclial Sciences of Jiangsu (2016SJB630038).

\section{References}

[1]. Guan Peahen. The time horn for building a powerful country of education. Ganging Daily, 2017$10-31$.

[2]. The Social Science Committee of the Ministry of Education. Guidelines for the evaluation of philosophy and social sciences in colleges and universities. Higher Education Press, 2016, p. 6.

[3]. Zhu Juwan, Liu Nuance. Research assessment: fitting methods to aims. Peking University Education Review, Vol. 10 (2012) No. 3, p. 47-56.

[4]. Jin, B. H, Rousseau, R. China's quantitative expansion phase: exponential growth but low impact.10th International Conference of the International Society for Scientometrics and Informatics. Sweden, Jul 24-28, 2005, p. 145-151.

[5]. Li Goodie. SCI is not the only criterion for evaluating scientific research achievements. Ganging Daily, 2006-10-24.

[6]. Feng Haiyan. Approaches to the reform of scientific research evaluation system in colleges and universities. Chinese University Technology Transfer. Vol. 10 (2006) No. 12, p. 56-57. 